\title{
Effects of Di-(2-Ethylhexyl) Phthalate At Environmentally Relevant Concentrations On Oxidative Stress and Lipid Metabolism in Livers of Male Xenopus Tropicalis
}

\section{Xinying Pan}

Guangdong University of Technology

\section{Li Zheng ( $\nabla$ zhengli8244@126.com)}

Guangdong University of Technology - University Town Campus: Guangdong University of Technology https://orcid.org/0000-0002-6790-8940

\section{Yong Ding}

Guangdong University of Technology

\section{Zhuo Dai}

Guangdong University of Technology

\section{Xufeng Qi}

Jinan University

\section{Xiaochun Zhang}

Guangdong University of Technology

\section{Yanbin Xu}

Guangdong University of Technology

\section{Guangyan Xie}

Guangdong University of Technology

\section{Qingxia Qiao}

Guangdong University Of Technology

\section{Research Article}

Keywords: Xenopus tropicalis, Di-(2-ethylhexyl) phthalate, Oxidative stress, Lipid metabolism, Environmentally relevant concentrations, Environmental toxicology

Posted Date: November 2nd, 2021

DOI: https://doi.org/10.21203/rs.3.rs-976295/v1

License: (c) (i) This work is licensed under a Creative Commons Attribution 4.0 International License. Read Full License 
Page 2/24 


\section{Abstract}

Di-(2-ethylhexyl) phthalate (DEHP), used as a popular plasticizer to enhance the flexibility of plastics, is a major pollutant in aquatic environments. DEHP poses severe risks to aquatic organisms since it is an endocrine-disrupting compound. To comprehensively evaluate the toxicity of DEHP on the growth and livers of male $X$. tropicalis, sexually mature male $X$. tropicalis were exposed to environmentally relevant concentrations of DEHP, $0.2,0.6,1.8,5.4 \mathrm{mg} / \mathrm{L}$, for 49 days. The results showed that DEHP had a severe toxic effect on the livers of male $X$. tropicalis. Histopathological analysis of livers in all the DEHP-exposed groups showed changes in terms of vacuolization, loose cell cords, and an increasing amount of melanin. Large lipid droplets were markedly formed, and there were changes in the mitochondrial morphology upon DEHP exposure. In addition, oxidative stress was induced through the suppression of biochemical indicators and the downregulation in the mRNA expression of genes ( $n r f 2$, cat, sod, gst, and $g p x$ ) related to oxidative stress. A reduction in expression of fatty acid metabolism-related genes ( $p p a r a$ ) was seen post-DEHP exposure. Thus, our study suggests that the hepatotoxicity induced by DEHP could be attributed to oxidative stress and disordered fatty acid metabolism. In conclusion, long-term exposure to DEHP at environmentally relevant concentrations poses ecological risks to aquatic organisms, which serves as a reminder that the application of DEHP and other plasticizers should be limited.

\section{Introduction}

Di-(2-ethylhexyl) phthalate (DEHP) is a plasticizer that is widely used in the manufacture of flexible plastics and plastisol (Staples et al. 1997). In addition to its close correlation to the plastic production industry, DEHP is also used as an additive in cosmetics, pharmaceuticals, and other fields (Chen et al. 2019; Zhao et al. 2020; Tang et al. 2020). DEHP is used widely, with a worldwide annual production of plastics as high as 394,000 tons (Xu et al. 2008; Yang et al. 2020). Because DEHP integrates with polymer materials via non-covalent bonding, it can readily liberate from plastics into the environment upon alteration of environmental conditions (Keresztes et al. 2013). DEHP can be detected in human blood, hair, and urine samples (Chang et al. 2013; Guo et al. 2010). With a similar structure of endogenous hormones, DEHP possess estrogen-like effect bind to nuclear receptor, and even induce or inhibit some biological processes (Zhang et al. 2021). Since it is closely associated with high risks to both humans and the natural environment, the ecotoxicity of DEHP deserves further investigations.

Surface water, which forms a crucial part of the natural environment, can be the main flow route of DEHP pollution. DEHP is the predominant phthalate detected in environmental water media (Kaneco et al. 2006). Our study collected and presented the environmental concentration distribution of DEHP in the surface water of China (Supplementary Information, Fig. S1 and Table. S1), which includes data from rivers, lakes, source water, freshwater ponds, and estuaries. The lowest concentration in China was detected in Changjiang River Estuary, at $0.26 \mathrm{ng} / \mathrm{L}$ (Zhang et al. 2017; Junaid et al. 2018). Studies also found a lower scope of DEHP distribution in the aquaculture fish-ponds (14.2-35.7 $\mu \mathrm{g} / \mathrm{L})$ and estuaries (0.57-5.62 $\mu \mathrm{g} / \mathrm{L}$ ) of the Pearl River, as compared to other basins in China (Cheng et al. 2019; Weizhen et al. 2020). Similar distributions of DEHP concentrations have been reported in the Yangtze and Haihe 
rivers, in the ranges of 6.35-91.22 $\mu \mathrm{g} / \mathrm{L}$ and 13.04-190.10 $\mu \mathrm{g} / \mathrm{L}$, respectively (Ai et al. 2021; Liu et al. 2020). The Yellow River basin, one of the drainage basins that suffers from the most severe DEHP contamination in China, has been reported to have a DEHP concentration of up to $6.35 \mathrm{mg} / \mathrm{L}$ (Pu et al. 2020). The detection frequency of DEHP reached up to $95 \%$ in most of the aquatic mediums and the highest concentration in China was detected in the Liao River, at as high as $13.05 \mathrm{mg} / \mathrm{L}$ (Zhang et al. 2017; Junaid et al. 2018). Most of these concentrations greatly exceed the limit level of DEHP $(8.00 \mu \mathrm{g} / \mathrm{L})$ according to the Chinese environmental quality standard and deserve further concerns regarding the ecological risk posed by them (Xu et al. 2011). Since the environmentally relevant concentrations selected in our study were based on the current range of DEHP concentration in China, these involved not only doses in the level of $\mu \mathrm{g} / \mathrm{L}$, but also above $1 \mathrm{mg} / \mathrm{L}$.

Exposure to high concentrations $(120,150$, and $200 \mathrm{mg} / \mathrm{L})$ of DEHP inhibited the heart rate and cartilage development of Danio rerio (Pu et al. 2020). After long-term exposure to DEHP in Coturnix japonica, there was occurrence of hepatotoxicity mediated by alterations in mitochondrial function and redox homeostasis (Zhang et al. 2019). Some studies also found that the reproductive toxicity in Oreochromis niloticus caused by DEHP is related to significant changes in genes involved in sex hormone synthesis (Zhang et al. 2018). However, these studies mostly focused on the toxicity of DEHP to mammals and fish, and there are few relevant studies on amphibians. Few studies have evaluated the toxic effects of DEHP by studying both the pathological changes and changes of molecular biology on amphibians. Thus, our study investigated the development and growth toxicity of DEHP in amphibians by means of pathological and molecular biology assessments.

Compared to other animal models, $X$. tropicalis is an advantageous model organism for evaluating the toxic effect of DEHP, because its genomic library has been constructed completely and it is similar to humans in many biological processes (Ishii et al. 2004; Zhao et al. 2021). Thus, in this study, male $X$. tropicalis were exposed to environmentally relevant concentrations of $\operatorname{DEHP}(0.2,0.6,1.8$, and $5.4 \mathrm{mg} / \mathrm{L})$ for 49 days, to identify the ensuing toxic effects. The main aims of the current study were to: (1) identify the organs targeted by the toxic effects of DEHP at environmentally relevant concentrations through the developmental index and pathological assessment; (2) determine the toxic effects of DEHP on target organs by means of biochemical assessment; and (3) clarify the molecular mechanism of the toxic effects using real-time quantitative reverse transcription PCR (qRT-PCR).

\section{Materials And Methods}

\subsection{Maintenance of $X$. tropicalis}

Throughout the whole experiment, adult $X$. tropicalis were selected in aquariums with circulating system that was kept running continuously in order to ensure adequate dissolved oxygen $(6.0 \mathrm{mg} / \mathrm{L}<$ concentration $<7.5 \mathrm{mg} / \mathrm{L}$ ). The aquariums were installed in our laboratory, maintained the temperature in the range of $24^{\circ} \mathrm{C}$ to $28^{\circ} \mathrm{C}$, and provided a light supply with $12 \mathrm{~h}$ light and $12 \mathrm{~h}$ dark. In addition, exposure solution was monitored in these conditions: $\mathrm{pH} 7.4 \pm 0.5$; hardness $128.5 \pm 15.2 \mathrm{mg} / \mathrm{L}$, in terms of $\mathrm{CaCO}_{3}$. 
All animal protocols and procedures were approved by the Institutional Animal Care and Use Committee of Guangdong University of Technology (No. GDUTXS002).

\subsection{Chronic exposure and tissue pre-processing}

The male frogs were randomly selected and exposed to the following treatments for 49 days: control group ( $0 \mathrm{mg} / \mathrm{L}$, contained $0.01 \%$ dimethyl sulfoxide), $0.2 \mathrm{mg} / \mathrm{L}, 0.6 \mathrm{mg} / \mathrm{L}, 1.8 \mathrm{mg} / \mathrm{L}, 5.4 \mathrm{mg} / \mathrm{L}$ of DEHP. A series of DEHP treatments were produced by diluting the DEHP stock solution (contained $0.01 \%$ dimethyl sulfoxide, DMSO) in dechlorinated deionised water, while the control group contained deionised water with $0.01 \%$ DMSO. Each group was conducted in an aquarium that had 5 male frogs, which represented five replicates. The volume of the exposed system was $25 \mathrm{~L}$ in each group. It is necessary to highlight that the lowest exposure concentration of $0.2 \mathrm{mg} / \mathrm{L}$ was chosen based on the DEHP level reported in the Haihe river (Liu et al. 2020). During the exposure period, the frogs were fed once every two days, and the exposure solution of each treatment was replaced once every two days, to maintain an accurate concentration of DEHP. The total body weight of the frogs was recorded every seven days. After 49 days of exposure, the frogs were frozen on ice for euthanization, and the tissues of the liver, heart, lung, stomach, and intestines were rinsed and immediately weighed on an electronic scale for evaluation of growth, following which they were stored at $-80^{\circ} \mathrm{C}$ for further assessment. It is worth mentioning that the stomach and intestines were weighted empty. The relative weight (Organ weights/The total body weight) of organs was used to evaluate the variations in growth after exposed to DEHP. The hepatosomatic index (HSI) was expressed as the ratio of the weight of the liver to the total weight of the male frog.

\subsection{Analysis of DEHP in solution}

The practical concentrations of DEHP were measured in $\mathrm{T}_{0}$ (in the time of replacement) and $\mathrm{T}_{48}$ (48 hours after replacement). The exposure solution for each treatment was used for gas chromatography tandem mass spectrometer (7890B-7000C, Aglient, California, USA). The analytical conditions were provided in Supplementary Information.

\subsection{Histology}

Dehydration of organs and tissues (liver, heart, lung, stomach, intestine) from the control and DEHP treatment groups was carried out using a gradient concentration of alcohol. Following that, the tissues were embedded in paraffin wax, sliced to pieces of $4 \mu \mathrm{m}$ thickness, and then dyed in a solution of hematoxylin-eosin (HE). The results of HE found that liver was the organ with the most obvious histopathological changes, compared to other organs (Supplementary material, Results of histopathology of organs, Fig. S3-S6). Based on the relative weight changes and histopathological changes, liver is speculated to be one of the organs that were most affected by DEHP on male $X$. tropicalis.

After fixation in the fixative for more than $24 \mathrm{~h}$, livers tissues were placed in $15 \%$ sucrose solution at $4^{\circ} \mathrm{C}$ and then transferred into $30 \%$ sucrose solution for $4^{\circ} \mathrm{C}$ dehydration. Finally, the processed tissues were embedded, sectioned into 8-10 $\mu \mathrm{m}$-sized pieces, and stained with Oil Red O. Histological samples were observed and photographed under an optical microscope (CX43, Olympus, Japan), at a magnification of 
$100 x$ and $400 x$. The area of the lipid droplets was analysed using Image $J$ software $(\mathrm{NIH}$, Windows version, USA), according to a previous study (Deutsch et al. 2014). Five sections selected at random from Red $O$ Oil staining in each treatment group were analysed.

\subsection{Ultrastructural analysis}

Fresh liver tissue was cut into $1 \mathrm{~mm}^{3}$ pieces, fixed in $1 \%$ osmic acid solution $(\mathrm{pH}=7.4)$, and then rinsed three times in phosphoric acid buffer ( $\mathrm{pH}=7.4)$. After dehydration in a gradient concentration of alcohol, the tissues were penetratively embedded in embedding agent. The resin block in the ultrathin slicer was cut into 60-80 nm ultrathin slices (15-UL, Daitome, Swiss Confederation), stained with $2 \%$ uranium acetate-saturated alcohol solution, and observed under a transmission electron microscope (HT7800/HT7700, Hitachi, Japan), and analysed.

\subsection{Biochemical analysis}

The reactive oxygen species (ROS) content was measured using the by dihydroethidium (DHE) method (Coll Ferrer et al. 2013). Frozen sections of the livers were incubated in DHE solution for $30 \mathrm{~min}$ at $37^{\circ} \mathrm{C}$, and then washed three times with phosphate buffered saline $(\mathrm{pH}=7.4)$. The residual liquid was cleaned, and the sections were buried in antifade mounting medium. The treated sections were scanned using fluorescence microscopy (Eclipse C1, Nikon, Japan) at an excitation wavelength of 510-560 nm. The fluorescence pictures were captured, and the intensity of fluorescence was used to determine the ROS content using ImageJ software ( $\mathrm{NIH}$, Windows version), Determination of antioxidant capacity included assessments of the activities of total superoxide dismutase (SOD), catalase (CAT), glutathione peroxidase (GPX), and glutathione-S-transferase (GST), as well as, malondialdehyde (MDA) and glutathione (GSH) content. The antioxidant index was measured using commercial assay kits (Nanjing Jiancheng Bioengineering Institute, Nanjing, China), according to the specifications of the manufacturer. SOD activity was determined based on the degree to which hydroxylamine can be oxidised by superoxide anion radicals (Beauchamp and Fridovich 1971). CAT activity was determined based on the consumption of hydrogen peroxide (Czihak 1984). GPX activity was evaluated in terms of the reduced glutathione consumed in the body (Tamura et al. 1982). The content of GSH was evaluated in terms of the combination of sulfhydryl with 5,5-dithiobis (2-nitrobenzoic acid), which can reflect the activity of GST (Griffith, 1980). MDA can combine with thiobarbituric acid (TBA) resulting in the generation of red products at $532 \mathrm{~nm}$ (Buege and Aust 1978). Three replicates were set for each group. The activity unit (U per $\mathrm{mg}$ protein; $\mathrm{U}$ per $\mathrm{g}$ protein) was performed to reflect the antioxidant capacity.

\section{7 qRT-PCR}

Total RNA was extracted from liver samples of the different groups using Trizol reagent (Ambion ${ }^{\mathrm{TM}}$, ThermoFisher, USA) and rinsed with $75 \%$ alcohol to remove the impurity and residual liquids. An ultramicro spectrophotometer (NanoDrop One ${ }^{\mathrm{TM}}$, ThermoFisher) was used to measure the concentration and quality of the obtained total RNA. cDNA synthesis was performed using the qPCR reverse transcription kit (FSQ-101, Toyobo, Japan) with efficient Oligo dT primers in a PCR amplifier (Mastercycler ${ }^{\circledR}$, Eppendorf, Germany). The amplification of cDNA was performed using SYBR ${ }^{\text {TM }}$ Green qPCR Mix (QPS-201, Toyobo) 
and a real-time PCR detection system with a two-step qRT-PCR procedure and a CFX Connect Module (Bio-Rad, Berkeley, USA). The reaction volume was $20 \mu \mathrm{L}$ under the following conditions: denaturation at $95^{\circ} \mathrm{C}$ for $1 \mathrm{~min}$, followed by 40 cycles at $95^{\circ} \mathrm{C}$ for $15 \mathrm{~s}$ and $60^{\circ} \mathrm{C}$ for $45 \mathrm{~s}$. Detailed information about the primer sequences used is presented in Supplementary Information, Table. S2. The relative expression (fold change of control group) of the target genes was calculated using the $2^{-\Delta \Delta C t}$ method (Kinoshita et al. 1992) and the gene ornithine decarboxylase was used as the reference gene (Dhorne-Pollet et al. 2019). Three replicates were set for each group.

\subsection{Statistical analysis}

Data have been expressed as mean \pm standard deviation (SD), and the data were tested for normality. Total body weight, relative weight of organs, fluorescence levels, and the content of antioxidants were statistically analysed by one-way ANOVA. The least significant difference (LSD) test was used to test for significant differences between the control and DEHP treatment (version 26.0; SPSS, USA), and the differences were considered statistically significant at $* P<0.05$, and $* * P<0.01$.

\section{Results And Discussion}

\subsection{Exposure concentration}

Measurement of the concentrations of di-(2-ethylhexyl) phthalate (DEHP) was displayed in Supplementary Information, Table. S3. The deviations between the nominal concentrations and experimental concentrations of DEHP was less than $20 \%$. Thus, the nominal concentrations of DEHP can represent the experimental concentrations of DEHP used in the study.

\subsection{Effects of DEHP on the developmental indicators of male Xenopus tropicalis}

In order to explore the influence of DEHP on the growth and development of male $X$. tropicalis, in the current study, we measured the total body weight (Fig. 1a), HSI (Fig. 1b), and the relative weight of organs (heart, stomach, and intestines) (Fig. S2) of male $X$. tropicalis. The total body weight of the frogs in the different groups $(0.2,0.6,1.8$, and $5.4 \mathrm{mg} / \mathrm{L})$ were reduced by $0.16,1.03,0.37$, and $0.96 \mathrm{~g}$, respectively, on exposure day 49 , as compared to that on day 0 (Fig. 1a). These results were similar to those of peer studies, which found that long-term DEHP exposure reduced the weight of Poecilia reticulata and Pseudobagrus fulvidraco (Jee et al. 2009; Zanotelli et al. 2010). It has also been revealed that the endocrine disrupter possesses estrogen-like features, which inhibit growth-related endogenous hormones, resulting in restricted growth (Nugegoda and Kibria 2017; Jia et al. 2016). This may be the reason why the total weight of the frogs post-DEHP treatment was lower than that before treatment. $0.6 \mathrm{mg} / \mathrm{L}$ group caused the most obvious reduction of total body weight, contrasted with other groups (Fig. 1a). This difference may be related to the fact that male frogs ate more bloodworm feed, so that they can acquire more energy and resist severe interference from DEHP (Yuan et al. 2017). 
There was no difference in relative weights of the lungs, stomach, and intestines between the control and DEHP groups (Fig. S2). Liver is an important organ involved in the metabolic process and detoxification process of vertebrates (Kabir et al. 2015). An increase in HSI was shown in Fig. 1b $(P<0.05)$. The increase in $\mathrm{HSI}$ of the liver may be due to disturbed lipid metabolism and lipid accumulation (Meng et al. 2018; Mo et al. 2019). Above results indicated that the liver is one of the target organs for DEHP toxicity to male $X$. tropicalis. Moreover, the liver is an organ that is directly attacked by xenobiotics, making it a suitable organ for assessing the toxicity of external pollutants (Różanowska et al. 1999). Thus, further studies need to be conducted on the hepatotoxicity caused by DEHP in male frogs.

\subsection{Effects of DEHP on the histopathology of livers}

HE staining was applied to observe the cellular morphology, to determine whether DEHP caused structural damage to livers. On the other hand, Oil Red $O$ stains the lipids, and thus, the Oil Red O-stained area reflects the lipid content in livers. Liver is the potential organ that were most affected by DEHP on male $X$. tropicalis. Therefore, the toxic effects mediated by DEHP to livers was further explored through the histopathological alterations.

The liver samples were subjected to HE (Fig. 2) and Oil Red O (Fig. 3) staining. Normal hepatocytes, distributed in a concentric circle, with obvious and neat morphology, were observed in the control group (Fig. 2a). Vacuolization of cytoplasm occurred in $0.2 \mathrm{mg} / \mathrm{L}$ DEHP-treated group (Fig. 2b). However, the livers of the $0.6 \mathrm{mg} / \mathrm{L}$ DEHP-treated group not only displayed damage in terms of vacuolization of cytoplasm, but also severely loose cell cords (Fig. 2c). Vacuolization and diffuse margin of hepatocytes appeared in the 1.8 and $5.4 \mathrm{mg} / \mathrm{L}$ DEHP-treated groups (Fig. 2d-e). Moreover, our study exclusively observed atrophy and solidification of hepatocytes upon treatment with $5.4 \mathrm{mg} / \mathrm{L} \mathrm{DEHP} \mathrm{(Fig.} \mathrm{2e).} \mathrm{These}$ results indicated that long-term exposure to DEHP can damage the structure of the liver. In addition, the types and frequencies of liver damage increased with increasing DEHP dose. A similar result was seen in a previous study on quail, involving severe vacuolization, disorderly permutation of hepatocytes, and squeezed nucleus, upon exposure to a dose of $1000 \mathrm{mg} / \mathrm{kg}$ DEHP (Zhang et al. 2019). Our findings were in line with the outcome of a study by Ito et al. (2007), which showed that DEHP can cause fragmentation and necrosis of hepatocytes in Rattus norvegicus.

Our study observed pathological changes upon Oil Red $\mathrm{O}$ staining after DEHP exposure, characterised by an increase in melanin and accumulation of lipids (Fig. 3a-e). Conspicuous and increasing melanin was observed in the 0.2 and $0.6 \mathrm{mg} / \mathrm{L}$ DEHP-treated groups, because the important role of melanin is an important scavenger of xenobiotics and a powerful antioxidant for prevention of oxidative stress (Fig. 3bc; Barni et al. 2002; Fenoglio et al. 2005). The melanin in livers was probably present in macrophage aggregates (Cicero et al. 1982; Bani 2009). On the contrary, the amount of melanin decreased in the 1.8 and $5.4 \mathrm{mg} / \mathrm{L}$ DEHP-treated groups, possibly due to the occurrence of oxidative stress and severe damage to the antioxidant system (Fenoglio et al. 2005; Fig. 3d-e). Fig. $3 f$ shows that the Oil Red 0stained area in livers treated with different doses of $\operatorname{DEHP}(0.2,0.6,1.8$, and $5.4 \mathrm{mg} / \mathrm{L})$ markedly increased by $0.61-, 0.69-, 0.83-$, and 1.04 -fold $(P<0.01)$, respectively, when compared to that in the control treatment. The results also reflected the accumulation of lipids upon DEHP exposure, in a dose-dependent 
manner. A similar outcome was observed in a previous study on Danio rerio, that is, DEHP could increase the lipid content of the liver (Forner-Piquer et al. 2017).

In a similar study, Zhang et al. (2019) illustrated that DEHP could restrain the metabolism of toxicants, thus amassing the toxic effect and causing injury to the liver. Therefore, the liver injury caused by DEHP at environmentally relevant concentrations, such as damaged hepatocyte structure and accumulation of lipids, may be attributed to the disturbed metabolism of toxicants in the liver.

\subsection{Effects of DEHP on the ultrastructure of livers}

The liver slices of male $X$. tropicalis were further scanned using transmission electron microscopy (TEM), to observe the hepatocyte microstructure of the hepatic cell membrane and organelles. The control group showed an integral liver cell structure, including tiny lipid droplets, obvious cell nuclei, and numerous oval mitochondria (Fig. 4a). A decrease in the number of mitochondria was observed in the 0.2 and $0.6 \mathrm{mg} / \mathrm{L}$ DEHP-treated groups (Fig. 4b-c). Swollen and deformed mitochondria were observed in both the 1.8 and $5.4 \mathrm{mg} / \mathrm{L}$ DEHP-treated groups, with more severe effects in the latter (Fig. $4 \mathrm{~d}-\mathrm{e}$ ). As a result, it can be seen that exposure to DEHP can cause mitochondrial damage. In addition, the liver sections in all the DEHPtreated groups were full of large lipid droplets (Fig. 4a-e), which indicated that lipid accumulation occurred upon DEHP exposure. Mitochondria are the target of exogenous toxic substances, and mitochondrial damage is related to changes in the antioxidant system (Li et al. 2014). Previous studies have concluded that mitochondria contain proteins involved in lipid metabolism and regulate energy generation by decomposing lipids (Jiang et al. 2014; Regnault et al. 2016; Chai et al. 2017). Therefore, the results suggest that DEHP at environmentally relevant concentrations may cause toxic effects by inhibiting mitochondrial function in the liver, leading to the accumulation of lipids and inhibition of antioxidant capacity.

\subsection{Effects of DEHP on oxidative stress}

Antioxidants include antioxidant enzymes and non-enzymatic scavengers, which adjust the production and removal of ROS to maintain dynamic homeostasis (Liang and Yan 2020). However, excessive ROS production is stimulated by external pollutants (Dogan et al. 2011), which may attack the biological macromolecules of the cell and produce lipid peroxidation products, such as MDA. Due to the inhibition of antioxidant functions, there is occurrence of oxidative stress and damage (Pandey et al. 2003). In order to examine whether DEHP caused oxidative stress in livers of male $X$. tropicalis, we determined the ROS content (Fig. 5), activities of antioxidant substances (Fig. 6a-e), and MDA content (Fig. 6f) in the livers subjected to different DEHP treatments.

As shown in Fig. 5a-e, the amount of ROS in the liver was determined by measuring the intensity of red fluorescence. The fluorescence intensity in $0.2,0.6,1.8$, and $5.4 \mathrm{mg} / \mathrm{L}$ DEHP-treated groups dosedependently and significantly increased by $0.064-, 0.56-, 0.71-$, and 0.76 -fold, respectively, relative to the control group ( $P<0.05$ and $P<0.01$ ) (Fig. 5f). Huang et al. (2019) noted that the ROS in Mus musculus livers increased when they were exposed to DEHP at doses of 125,250 , and $375 \mathrm{mg} / \mathrm{kg} /$ day. Compared to the rats, the male $X$. tropicalis may be more sensitive to DEHP, because the ROS produced in their livers 
were in response to environmentally relevant concentrations of DEHP. This suggests that the male $X$. tropicalis is suitable for studying DEHP pollution in the water environment, especially in case of lower environmental concentrations of DEHP. Moreover, this result indicated that excessive ROS was produced upon DEHP treatment, and it is possible that a lack of antioxidant substances was used to eliminate the ROS (Amado and Monserrat 2010; Gavrilovic et al. 2021).

Antioxidants, including antioxidant enzymes (SOD, CAT, GST, and GPX) and non-enzymatic scavengers (GSH), are known biomarkers of oxidative stress (Kobayashi and Yamamoto 2006; Liu et al. 2019).

Fig. 6 a shows that the activity of SOD enzymes in the livers treated with $0.2,0.6,1.8$, and $5.4 \mathrm{mg} / \mathrm{L} \mathrm{DEHP}$ increased by $0.30-, 0.29-, 0.14-$, and 0.02 -fold, respectively, as compared to that in the control group. There was an activity peak at $0.6 \mathrm{mg} / \mathrm{L}$ DEHP, and SOD enzymes presented significant differences upon DEHP treatment, except the group treated with $5.4 \mathrm{mg} / \mathrm{L} \mathrm{DEHP}(P<0.05)$ (Fig. 6a). CAT and GST activities tended to be similar to that of SOD. These increased significantly $(P<0.05$ and $P<0.01)$ with increasing DEHP concentration, peaked at $0.6 \mathrm{mg} / \mathrm{L} \mathrm{DEHP,} \mathrm{and} \mathrm{then} \mathrm{decreased} \mathrm{at} 5.4 \mathrm{mg} / \mathrm{L} \mathrm{DEHP} \mathrm{(Fig.} 6 \mathrm{~b}-\mathrm{c}$ ). The GPX activity displayed an upward trend in all of the DEHP groups, compared to the control group, and reached a peak at $0.6 \mathrm{mg} / \mathrm{L} \mathrm{DEHP} \mathrm{(Fig.} \mathrm{6d).} \mathrm{The} \mathrm{decrease} \mathrm{in} \mathrm{the} \mathrm{activities} \mathrm{of} \mathrm{the} \mathrm{antioxidant} \mathrm{enzymes}$ post-DEHP exposure was in line with the findings in mouse and human endometrial stromal cells (You et al. 2014; Cho et al. 2015). Meanwhile, this result revealed that inhibited antioxidant defence activity was observed at doses above $0.6 \mathrm{mg} / \mathrm{L}$ DEHP, which is also supported by the formation of ROS. As an important scavenger of ROS, GSH is highly correlated with the antioxidant capacity of the liver (Liang and Yan 2020). In our study, the GSH content of $0.2,0.6,1.8$, and $5.4 \mathrm{mg} / \mathrm{L}$ DEHP-treated groups markedly decreased by $0.27-, 0.56-, 0.63-$, and 0.69 -fold, respectively, relative to the control group $(P<0.01)$ (Fig. 6e). The result of changes in the activities of antioxidants suggested that lower concentrations of DEHP ( 0.2 and $0.6 \mathrm{mg} / \mathrm{L}$ ) were able to improve the antioxidant ability of liver, while impaired antioxidant functions were induced by higher concentrations (1.8 and $5.4 \mathrm{mg} / \mathrm{L}$ ). MDA content plays an important role in reflecting the degree of oxidative damage (Zou et al. 2015). As shown in Fig. 6f, at 0.2, 1.8, and 5.4 $\mathrm{mg} / \mathrm{L}$ DEHP, the MDA content increased with increasing dose $(P<0.05)$. However, the MDA content decreased slightly upon treatment with $0.6 \mathrm{mg} / \mathrm{L} \mathrm{DEHP,} \mathrm{because} \mathrm{the} \mathrm{high} \mathrm{levels} \mathrm{of} \mathrm{antioxidant} \mathrm{functions}$ removed excessive ROS and maximised protection against oxidative stress (Zhao et al. 2014).

Excessive ROS, imbalance in antioxidants, and MDA content are used as major biomarkers of oxidative stress in organisms (Kobayashi et al. 2006; Marrocco et al. 2017). Our study findings suggested that DEHP induced oxidative stress in the liver. In addition, oxidative stress is strongly related to the toxic effects of DEHP on the liver, especially in terms of the histopathological biomarkers (Ben Ameur et al. 2012; Zhang et al. 2019). Therefore, oxidative stress might have played a significant role in mediating the liver structural damage in the previous histopathological analyses.

\subsection{Effect of DEHP on genes related to oxidative stress and lipid metabolism}


To further elucidate the molecular mechanism of oxidative stress and lipid accumulation, the transcription of related genes was investigated in the livers of male $X$. tropicalis (Fig. 7). Long-term exposure to $\operatorname{DEHP}(0.2,0.6,1.8$, and $5.4 \mathrm{mg} / \mathrm{L})$ significantly decreased the expression of $n r f 2$ in the liver to 0.30-, 0.31-, 0.33-, and 0.39-fold, respectively, of that in the control treatment $(P<0.01)$ (Fig. 7a). Nuclear factor erythrocyte 2-related factor 2 (encoded by $n$ rf2) is a nuclear transcription factor that plays a crucial role in activating the antioxidant defence system in response to oxidative stress and excessive ROS (Osburn and Kensler 2008; Shaw et al. 2019). Upon exposure to 0.2, 0.6, 1.8, and $5.4 \mathrm{mg} / \mathrm{L} \mathrm{DEHP,} \mathrm{the}$ mRNA expression of sod increased with 1.24-, 1.06-, 0.30-, and 0.28-fold, respectively, of that in the control treatment (Fig. 7b). The transcription of cat was obviously increased in the 0.6 and $1.8 \mathrm{mg} / \mathrm{L}$ DEHP-exposed groups, but slightly inhibited in $5.4 \mathrm{mg} / \mathrm{L}$ DEHP-exposed group, as compared to that in the control group $(P<0.01)$ (Fig. 7c). The gene expression of gst was significantly increased in the 0.2 and $0.6 \mathrm{mg} / \mathrm{L}$ DEHP-exposed groups, while it decreased in the 1.8 and $5.4 \mathrm{mg} / \mathrm{L}$ DEHP-exposed groups, when compared to the control group $(P<0.01)$ (Fig. 7d). The mRNA level of gpx showed an obvious increase in all the DEHP treatments $(P<0.05$ and $P<0.01)$ (Fig. 7e). Downstream antioxidant enzyme genes (cat, sod, $g p x$, and $g s t$ ), regulated by $n r f 2$, also have an outstanding protective effect to oxidative stress (Cavin et al. 2008). From these results, it can be seen that the expression patterns of antioxidant genes correspond to those of the antioxidant enzymes. In addition, the present study indicated that the livers of $X$. tropicalis males had a certain degree of resistance to the toxic effects of low concentrations of DEHP, activating genes related to oxidative stress, and highly stimulating the antioxidant function of the organism, to prevent oxidative damage. However, the antioxidant function was suppressed because of the decreased antioxidant genes at higher concentrations. Our outcome was in contrast with the suppressed mRNA transcriptional expression of oxidative stress genes (sod, cat, and gst) observed in case of Oryzias latipes exposed to DEHP at environmentally relevant concentrations, although the concentrations used in that study were ten times lower than those used in the present study, and the variations were due to different exposure times to DEHP and the different resistance systems of the organisms (Yang and Li 2018). Many studies have revealed that the activation of the nrf2 signalling pathway and downstream antioxidant enzyme genes prevents lipid peroxidation, structural damage, and disease in the livers (Gong and Cederbaum 2006; Gan et al. 2012). Therefore, the histopathological and biochemical findings in the current study presented evidence that the oxidative stress mediated by the suppression of antioxidant genes contributed to the production of lipid peroxidation products and damaged structures in the liver.

Based on the histopathological and ultrastructural findings of the study, it can be speculated that lipid accumulation occurred upon DEHP exposure. Lipid accumulation contributes to the variation in lipid metabolism (Gorria et al. 2006; Circu and Aw 2010; Ramesh et al. 2015; Meng et al. 2018; Li et al. 2020). In this study, the transcription levels of genes related to lipid metabolism were used to determine the molecular mechanism of variation in lipid metabolism. Downregulation of ppara expression was observed in all the DEHP-exposed groups. DEHP concentrations of $0.2,0.6,1.8$, and $5.4 \mathrm{mg} / \mathrm{L}$ caused a marked decrease in the expression, by 0.16-, 0.21-, 0.27-, and 0.40-fold, respectively, as compared to the control treatment $(P<0.05$ and $P<0.01)$ (Fig. 7f). Peroxisome proliferator activated receptor-a (encoded 
by ppara) is a type of peroxisome proliferator-activated receptor that plays an important role in enhancing fatty acid $\beta$-oxidation capacity in the liver (Yang et al. 2007; Feige et al. 2010; Maradonna et al. 2013). Promotion of fatty acid $\beta$-oxidation is associated with the release of free fatty acids and inhibition of lipogenesis (Wei et al. 2018). The study by Adeogun et al. (2018) supported our results, indicating that there was a decrease in the expression of ppara in Clarias gariepinus, after dealing with the environmentally relevant concentrations of DEHP (200 and $400 \mu \mathrm{g} / \mathrm{L})$. In addition, published studies have indicated that the restrained activity of fatty acid $\beta$-oxidation could lead to excessive lipid accumulation and oxidative stress in the liver of Rattus norvegicus (Wierzbicki et al. 2009; Jia et al. 2015; Qin et al., 2016). According to the ultrastructural and histological results of our study, it can be determined that the mechanism of disordered fatty acid $\beta$-oxidation finally resulted in lipid accumulation and oxidative stress in the livers exposed to DEHP.

\section{Conclusions}

Our study is the first to investigate the growth and developmental toxicity caused by DEHP at environmentally relevant concentrations in male $X$. tropicalis. At environmentally relevant concentrations, DEHP induced hepatotoxicity in $X$. tropicalis, including histopathological damage, morphological changes in mitochondria, lipid accumulation, and oxidative stress. In addition, DEHP disturbed the expression of genes related to oxidative stress and lipid metabolism. In summary, the above results suggested that the resulting liver damage may arise from oxidative damage caused by the downregulation of oxidative stress genes, while lipid accumulation in the liver is mediated by the downregulation of lipid metabolism-related genes. There is a need for further studies focusing on other toxic end-points of hepatotoxicity caused by environmentally relevant concentrations of DEHP in $X$. tropicalis (e.g., alterations in metabolites and proteomics), as well as, a significant understanding of the mechanisms of toxicity in other aquatic models.

\section{Declarations}

\section{Ethical Approval and consent to participate}

All experiments and protocols were approved by the Committee on the Ethics of Animal Experiments of The Guangdong University of Technology (No. GDUTXS002).

\section{Consent for publication}

Not applicable.

\section{Competing interests}

The authors declare that they have no competing interests in this section.

\section{Availability of data and materials}


The datasets used and/or analysed during the current study are available from the corresponding author on reasonable request.

\section{Authors' contributions}

Conceptualization: Li Zheng, Xufeng Qi, Yanbin Xu; Review \& Editing: Xinying Pan, Li Zheng; Methodology: Li Zheng, Xufeng Qi, Yanbin Xu, Guangyan Xie, Qingxia Qiao; Writing - original draft preparation: Xinying Pan; Formal Analysis: Xinying Pan; Validation: Xinying Pan, Yong Ding, Zhuo Dai, Xiaochun Zhang; Funding acquisition: Li Zheng; Supervision: Li Zheng; Visualization: Visualization; Data curation: Xinying Pan. All authors have read and approved the published version of the manuscript.

\section{Acknowledgements}

This work was supported by grants from the National Natural Science Foundation of China (No. $31802025,4197070130)$, and the Key Laboratory of Regenerative Medicine, Ministry of Education, Jinan University (No. ZSYX-M-2019-00009), China.

\section{Funding}

The research leading to these results received funding from the National Natural Science Foundation of China under Grant Agreement No. 31802025, 4197070130.

\section{References}

1. Ai S, Gao X, Wang X, Li J, Fan B, Zhao S, Liu Z (2021) Exposure and tiered ecological risk assessment of phthalate esters in the surface water of Poyang Lake, China. Chemosphere 262:127864

2. Amado LL, Monserrat JM (2010) Oxidative stress generation by microcystins in aquatic animals: why and how. Environ Int 36:226-235

3. Barni S, Vaccarone R, Bertone V, Fraschini A, Bernini F, Fenoglio C (2002) Mechanisms of changes to the liver pigmentary component during the annual cycle (activity and hibernation) of Rana esculenta L. J Anat 200:185-194

4. Bani G (2009) Melanogenesi in cellule di kupffer di bufo bufo (L.) adulto. Bolletino Di Zoologia 33(2):269-282

5. Beauchamp C, Fridovich I (1971) Superoxide dismutase: Improved assays and an assay applicable to acrylamide gels. Anal Biochem 44:276-287

6. Ben Ameur W, de Lapuente J, El Megdiche Y, Barhoumi B, Trabelsi S, Camps L, Serret J, Ramos-López D, Gonzalez-Linares J, Driss MR, Borràs M (2012) Oxidative stress, genotoxicity and histopathology biomarker responses in mullet (Mugil cephalus) and sea bass (Dicentrarchus labrax) liver from Bizerte Lagoon (Tunisia). Mar Pollut Bull 64:241-251

7. Buege JA, Aust SD (1978) Microsomal lipid peroxidation. 52:302-310 
8. Cavin C, Marin-Kuan M, Langouet S, Bezencon C, Guignard G, Verguet C, Piguet D, Holzhäuser D, Cornaz R, Schilter B (2008) Induction of Nrf2-mediated cellular defenses and alteration of phase I activities as mechanisms of chemoprotective effects of coffee in the liver. Food Chemical Toxicology 46:1239-1248

9. Chai L, Chen A, Luo P, Zhao H, Wang H (2017) Histopathological changes and lipid metabolism in the liver of Bufo gargarizans tadpoles exposed to Triclosan. Chemosphere 182:255-266

10. Chang YJ, Lin KL, Chang YZ (2013) Determination of Di-(2-ethylhexyl) phthalate (DEHP) metabolites in human hair using liquid chromatography-tandem mass spectrometry. Clin Chim Acta 420:155159

11. Cheng Z, Liu JB, Gao M, Shi GZ, Fu XJ, Cai P et al (2019) Occurrence and distribution of phthalate esters in freshwater aquaculture fish ponds in Pearl River Delta, China. Environ Pollut 245:883-888

12. Cho YJ, Park SB, Han M (2015) Di-(2-ethylhexyl)-phthalate induces oxidative stress in human endometrial stromal cells in vitro. Mol Cell Endocrinol 407:9-17

13. Cicero R, Sciuto S, Chillemi R, Sichel G (1982) Melanosynthesis in the kupffer cells of amphibia. Comparative Biochemistry Physiology Part A Physiology 73(3):477-479

14. Circu ML, Aw TY (2010) Reactive oxygen species, cellular redox systems, and apoptosis. Free Radic Biol Med 48:749-762

15. Coll Ferrer MC, Eckmann UN, Composto RJ, Eckmann DM (2013) Hemocompatibility and biocompatibility of antibacterial biomimetic hybrid films. Toxicol Appl Pharmacol 272:703-712

16. Czihak E, Rüdiger W, Schulze K (1987) Behaviourally dependent modulation of lateral geniculate unit activity in the freely moving cat. Behav Brain Res 25(3):167-174

17. Deutsch MJ, Schriever SC, Roscher AA, Ensenauer R (2014) Digital image analysis approach for lipid droplet size quantitation of Oil Red O-stained cultured cells. Anal Biochem 445:87-89

18. Dogan D, Can C, Kocyigit A, Dikilitas M, Taskin A, Bilinc H (2011) Dimethoate-induced oxidative stress and DNA damage in Oncorhynchus mykiss. Chemosphere 84:39-46

19. Dhorne-Pollet S, Thélie A, Pollet N (2013) Validation of novel reference genes for rt-qpcr studies of gene expression in xenopus tropicalis during embryonic and post-embryonic development. Dev Dyn 242(6):709-717

20. Feige JN, Gerber A, Casals-Casas C, Yang Q, Winkler C, Bedu E et al (2010) The pollutant diethylhexyl phthalate regulates hepatic energy metabolism via species-specific PPARalpha-dependent mechanisms. Environ Health Perspect 118:234-241

21. Fenoglio C, Boncompagni E, Fasola M, Gandini C, Comizzoli S, Milanesi G (2005) Effects of environmental pollution on the liver parenchymal cells and Kupffer-melanomacrophagic cells of the frog Rana esculenta. Ecotoxicol Environ Saf 60:259-268

22. Gan L, Vargas MR, Johnson DA, Johnson JA (2012) Astrocyte-specific overexpression of Nrf2 delays motor pathology and synuclein aggregation throughout the CNS in the alpha-synuclein mutant (A53T) mouse model. J Neurosci 32:17775-17787 
23. Gong P, Cederbaum Al (2006) Nrf2 is increased by CYP2E1 in rodent liver and HepG2 cells and protects against oxidative stress caused by CYP2E1. Hepatology 43:144-153

24. Gorria M, Tekpli X, Sergent O, Huc L, Gaboriau F, Rissel M et al (2006) Membrane fluidity changes are associated with benzo[a]pyrene-induced apoptosis in F258 cells: protection by exogenous cholesterol. Ann N Y Acad Sci 1090:108-112

25. Griffith OW (1980) Determination of glutathione and glutathione disulfide using glutathione reductase and 2-vinylpyridine. Analytical Biochemistry 106:207-212

26. Guo ZY, Gai PP, Duan J, Zhai JX, Zhao SS, Wang S, Wei DY (2010) Simultaneous determination of phthalates and adipates in human serum using gas chromatography-mass spectrometry with solidphase extraction. Biomedical Chromatography 24:1094-1099

27. Huang Y, Wu C, Ye Y, Zeng J, Zhu J, Li Y et al (2019) The increase of ROS caused by the interference of DEHP with jnk/p38/p53 pathway as the reason for hepatotoxicity. International Journal of Environmental Research Public Health 16(3):356

28. Ishii Y, Asakawa S, Taguchi Y, Ishibashi S, Yagi T, Shimizu N (2004) Construction of BAC library for the amphibian Xenopus tropicalis. Genes Genetic Systems 79:49-51

29. Ito Y, Yamanoshita O, Kurata $Y$ et al (2007) Induction of peroxisome proliferator-activated receptor alpha (ppara)-related enzymes by di(2-ethylhexyl) phthalate (dehp) treatment in mice and rats, but not marmosets. Arch Toxicol 81:219-226

30. Jee JH, Koo JG, Keum YH, Park KH, Choi SH, Kang JC (2009) Effects of dibutyl phthalate and diethylhexyl phthalate on acetylcholinesterase activity in bagrid catfish, Pseudobagrus fulvidraco(Richardson). Journal of Applied Ichthyology 25:771-775

31. Jia PP, Ma YB, Lu CJ, Mirza Z, Zhang W, Jia YF, Li WG, Pei DS (2016) The Effects of Disturbance on Hypothalamus-Pituitary-Thyroid (HPT) Axis in Zebrafish Larvae after Exposure to DEHP. PLoS One 11:e0155762

32. Jia Y, Kim JH, Nam B, Kim J, Lee JH, Kim KO et al (2015) The dipeptide H-Trp-Arg-OH (WR) Is a PPARalpha agonist and reduces hepatic lipid accumulation in lipid-loaded H4IIE cells. Applied Biochemistry Biotechnology 175:1211-1220

33. Jiang Y, Xia W, Zhu Y, Li X, Wang D, Liu J et al (2014) Mitochondrial dysfunction in early life resulted from perinatal bisphenol $A$ exposure contributes to hepatic steatosis in rat offspring. Toxicol Lett 228:85-92

34. Junaid M, Jia PP, Tang YM, Xiong WX, Huang HY, Strauss PR et al (2018) Mechanistic toxicity of DEHP at environmentally relevant concentrations (ERCs) and ecological risk assessment in the Three Gorges Reservoir Area, China. Environ Pollut 242:1939-1949

35. Kabir ER, Rahman MS, Rahman I (2015) A review on endocrine disruptors and their possible impacts on human health. Environ Toxicol Pharmacol 40(1):241-258

36. Kaneco S, Katsumata H, Suzuki T, Ohta K (2006) Titanium dioxide mediated photocatalytic degradation of dibutyl phthalate in aqueous solution-kinetics, mineralization and reaction mechanism. Chemical Engineering Journal 125:59-66 
37. Keresztes S, Tatar E, Czegeny Z, Zaray G, Mihucz VG (2013) Study on the leaching of phthalates from polyethylene terephthalate bottles into mineral water. Sci Total Environ 458-460:451-458

38. Kinoshita T, Imamura J, Nagai H, Shimotohno K (1992) Quantification of gene expression over a wide range by the polymerase chain reaction. Analytical Biochemistry 206:231-235

39. Kobayashi M, Yamamoto M (2006) Nrf2-Keap1 regulation of cellular defense mechanisms against electrophiles and reactive oxygen species. Adv Enzyme Regul 46:113-140

40. Li F, Xiang B, Jin Y, Li C, Ren S, Wu Y (2020) Hepatotoxic effects of inhalation exposure to polycyclic aromatic hydrocarbons on lipid metabolism of C57BL/ 6 mice. Environ Int 134:105000

41. Li X, Fang EF, Scheibye-Knudsen M, Cui H, Qiu L, Li J, He Y et al (2014) Di-(2-ethylhexyl) phthalate inhibits DNA replication leading to hyperPARylation, SIRT1 attenuation, and mitochondrial dysfunction in the testis. Sci Rep 4:6434

42. Liang F, Yan B (2020) Oxidative damage in the liver and kidney induced by dermal exposure to diisononyl phthalate in Balb/c mice. Toxicol Ind Health 36:30-40

43. Liu Y, He Y, Zhang J, Cai C, Breider F, Tao S, Liu WX (2020) Distribution, partitioning behavior, and ecological risk assessment of phthalate esters in sediment particle-pore water systems from the main stream of the Haihe River, Northern China. Sci Total Environ 745:141131

44. Maradonna F, Evangelisti M, Gioacchini G, Migliarini B, Olivotto I, Carnevali O (2013) Assay of vtg, ERs and PPARs as endpoint for the rapid in vitro screening of the harmful effect of Di-(2-ethylhexyl)phthalate (DEHP) and phthalic acid (PA) in zebrafish primary hepatocyte cultures. Toxicol In Vitro 27:84-91

45. Marrocco I, Altieri F, Peluso I (2017) Measurement and Clinical Significance of Biomarkers of Oxidative Stress in Humans. Oxidative Med Cell Longev 2017:6501046

46. Meng FX, Li M, Song MZ, Yuan LX, Gong YF, Qian YX, Shi G, Wang RX (2018) Di-2-ethylhexyl phthalate (DEHP) exposure disturbs lipid metabolism in juvenile yellow catfish Tachysurus fulvidraco. J Fish Biol 92:85-93

47. Mo N, Zhang M, Wang R, Xia S, Meng F, Qian Y, Li M (2019) Effects of alpha-ethinyl estradiol (EE2) and diethylhexyl phthalate (DEHP) on growth performance, antioxidant status and immune response of juvenile yellow catfish Pelteobagrus fulvidraco. Comp Biochem Physiol C Toxicol Pharmacol 226:108615

48. Nugegoda D, Kibria G (2017) Effects of environmental chemicals on fish thyroid function: Implications for fisheries and aquaculture in Australia. Gen Comp Endocrinol 244:40-53

49. Pandey S, Parvez S, Sayeed I, Haque R, Binhafeez B, Raisuddin S (2003) Biomarkers of oxidative stress: a comparative study of river Yamuna fish Wallago attu (BI. \& Schn.). The Science of The Total Environment 309:105-115

50. Pu SY, Hamid N, Ren YW, Pei DS (2020) Effects of phthalate acid esters on zebrafish larvae: Development and skeletal morphogenesis. Chemosphere 246:125808

51. Qin SM, Yin JJ, Huang K (2016) Free Fatty Acids Increase Intracellular Lipid Accumulation and Oxidative Stress by Modulating PPARalpha and SREBP-1c in L-02 Cells. Lipids 51:797-805 
52. Ramesh A, Hood DB, Inyang F, Greenwood M, Nyanda AM, Archibong AE et al (2015) Comparative Metabolism, Bioavailability, and Toxicokinetics of Benzo [ a ] pyrene in Rats After Acute Oral, Inhalation, and Intravenous Administration. Polycyclic Aromat Compd 22:969-980

53. Regnault C, Willison J, Veyrenc S, Airieau A, Meresse P, Fortier M et al (2016) Metabolic and immune impairments induced by the endocrine disruptors benzo[a]pyrene and triclosan in Xenopus tropicalis. Chemosphere 155:519-527

54. Staples CA, Peterson DR, Parkerton TF, Adams WJ (1997) The environmental fate of phthalate esters: A literature review. Chemosphere 35:667-749

55. Tamura M, Oshino N, Chance B (1982) Some characteristics of hydrogen- and alkylhydroperoxides metabolizing systems in cardiac tissue. J Biochem 92:1019-1031

56. Wei CC, Luo Z, Hogstrand C, Xu YH, Wu LX, Chen GH et al (2018) Zinc reduces hepatic lipid deposition and activates lipophagy via Zn(2+)/MTF-1/PPARalpha and $\mathrm{Ca}(2+) /$ CaMKKbeta/AMPK pathways. FASEB J 32:fj201800463

57. Weizhen Z, Xiaowei Z, Peng G, Ning W, Zini L, Jian H, Zheng Z (2020) Distribution and risk assessment of phthalates in water and sediment of the Pearl River Delta. Environ Sci Pollut Res Int 27:12550-12565

58. Wierzbicki M, Chabowski A, Zendzian-Piotrowska M, Harasim E, Gorski J (2009) Chronic, in vivo, PPARalpha activation prevents lipid overload in rat liver induced by high fat feeding. Advances in Medical Sciences 54:59-65

59. Xu Q, Yin X, Shen Y, Zhang N, Wang M, Gu Z (2011) Detection of Phthalate Esters in Environmental Water Samples -Comparison of Nylon6 Nanofibers Mat-based Solid Phase Extraction and Other Conventional Extraction Methods. Chin J Chem 29:567-574

60. Yang Q, Li Y (2007) Roles of PPARs on regulating myocardial energy and lipid homeostasis. J Mol Med 85:697-706

61. Yang WK, Chiang LF, Tan SW, Chen PJ (2018) Environmentally relevant concentrations of di(2ethylhexyl) phthalate exposure alter larval growth and locomotion in medaka fish via multiple pathways. Sci Total Environ 640-641:512-522

62. Yang $Y$, Sun F, Chen $H$, Tan H, Huang Y (2020) Postnatal exposure to DINP was associated with greater alterations of lipidomic markers for hepatic steatosis than DEHP in postweaning mice. Science of The Total Environment 758:143631

63. You HH, Chen SH, Mao L, Li B, Yuan Y, Li R, Yang X (2014) The adjuvant effect induced by di-(2ethylhexyl) phthalate (DEHP) is mediated through oxidative stress in a mouse model of asthma. Food Chem Toxicol 71:272-281

64. Zanotelli VR, Neuhauss SC, Ehrengruber MU (2010) Long-term exposure to bis(2-ethylhexyl) phthalate (DEHP) inhibits growth of guppy fish (Poecilia reticulata). J Appl Toxicol 30:29-33

65. Zhang L, Hu Y, Sun W, Chen S, Jia X, Cai W (2018) Transcriptomic responses of Nile tilapia (Oreochromis niloticus) liver to environmental concentration of di(2-ethylhexyl) phthalate. Ecotoxicol Environ Saf 165:70-77 
66. Zhang Q, Zhao Y, Talukder M, Han Y, Zhang C, Li XN, Li JL (2019) Di(2-ethylhexyl) phthalate induced hepatotoxicity in quail (Coturnix japonica) via modulating the mitochondrial unfolded protein response and NRF2 mediated antioxidant defense. Sci Total Environ 651:885-894

67. Zhang ZM, Zhang HH, Li JL, Yang GP (2017) Determination of Phthalic Acid Esters in Seawater and Sediment by Solid-phase Microextraction and Gas Chromatography-Mass Spectrometry. Chin J Anal Chem 45:348-356

68. Zhang Y, Jiao Y, Li Z, Tao Y, Yang Y (2021) Hazards of phthalates (PAEs) exposure: a review of aquatic animal toxicology studies. Science of The Total Environment 771:145418

69. Zhao J, Luo W, Xu Y, Ling J, Deng L (2021) Potential reproductive toxicity of multi-walled carbon nanotubes and their chronic exposure effects on the growth and development of Xenopus tropicalis. Sci Total Environ 766:142652

70. Zhao X, Gao Y, Qi M (2014) Toxicity of phthalate esters exposure to carp (Cyprinus carpio) and antioxidant response by biomarker. Ecotoxicology 23:626-632

71. Zou P, Li K, Liu S, Xing R, Qin Y, Yu H, Zhou M, Li P (2015) Effect of chitooligosaccharides with different degrees of acetylation on wheat seedlings under salt stress. Carbohyd Polym 126:62-69

\section{Figures}
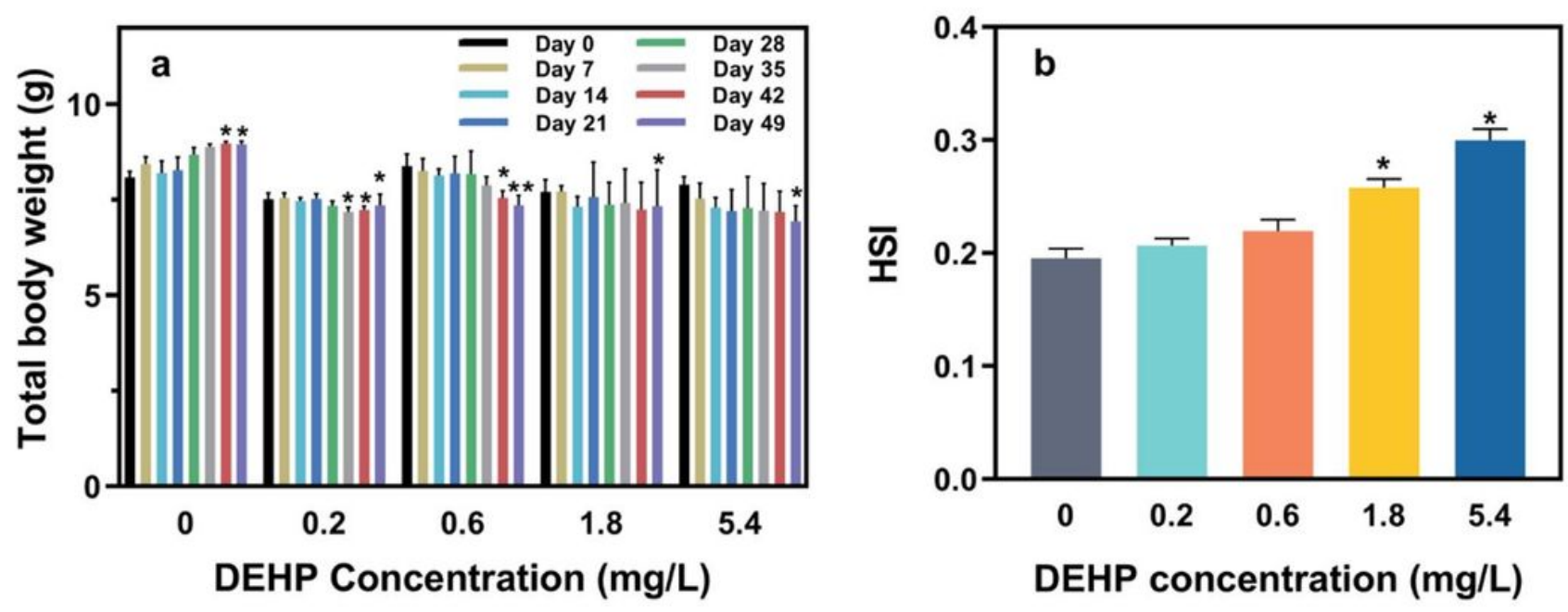

\section{Figure 1}

Effect of di-(2-ethylhexyl) phthalate (DEHP) exposure on developmental indicators. (a) Total body weight of male X. tropicalis. (b) Hepatosomatic index (HSI) of male X. tropicalis post-DEHP exposure. $\left({ }^{\star} P<0.05\right.$, ** $P<0.01$, there is a significant difference from the total body weight on Day $0 ; n=5$ ) 

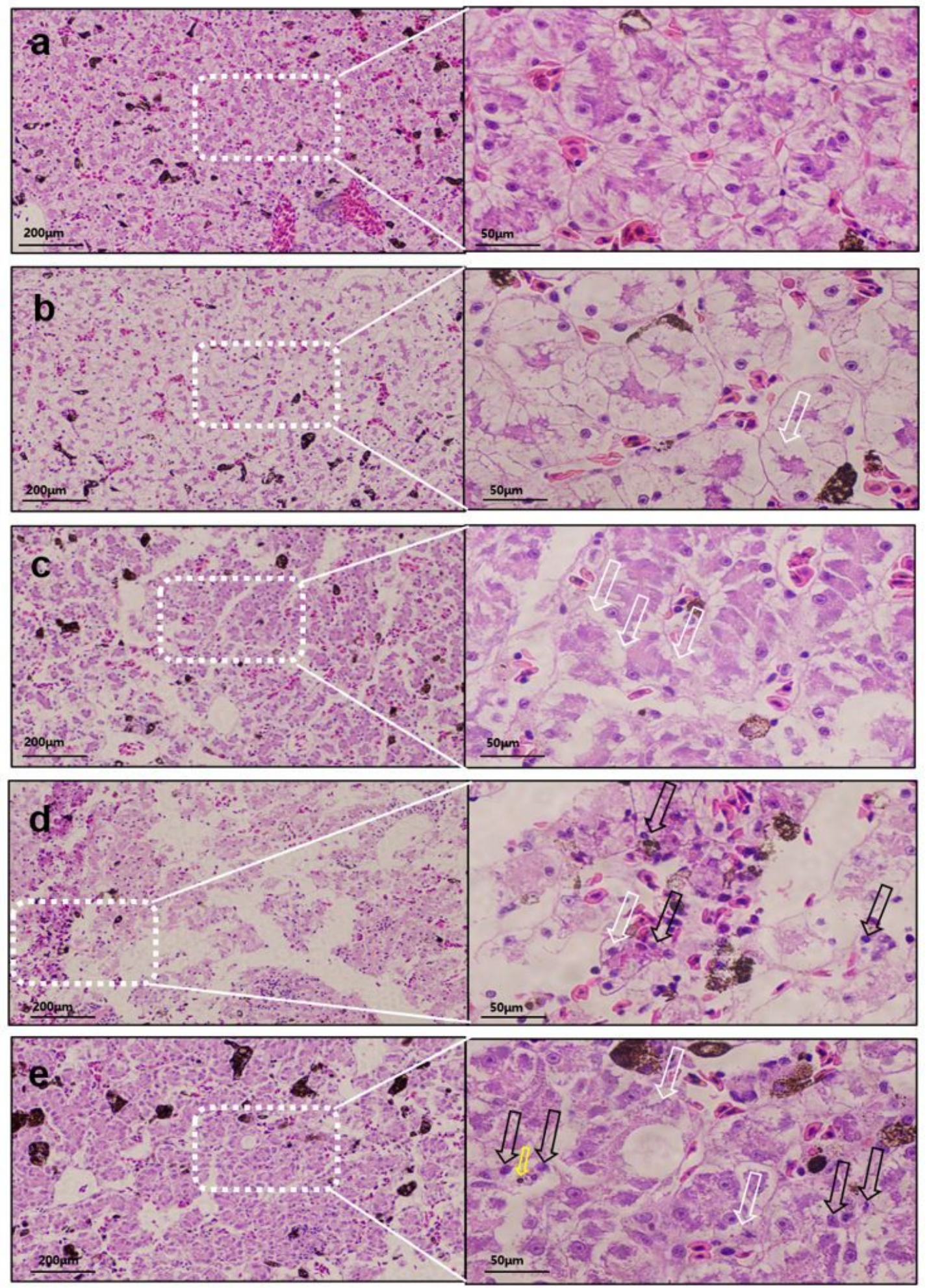

\section{Figure 2}

Histopathological images of hematoxylin-eosin (HE) staining in the livers of male X. tropicalis under 100x and 400x magnifications (a-e). (White arrows, black arrows, and yellow arrows show vacuolization of cytoplasm, loose cell cords, and solidification of hepatocytes, respectively; a, b, c, d and e represent livers from $0,0.2,0.6,1.8$ and $5.4 \mathrm{mg} / \mathrm{L}$ DEHP-treated groups, respectively.) 

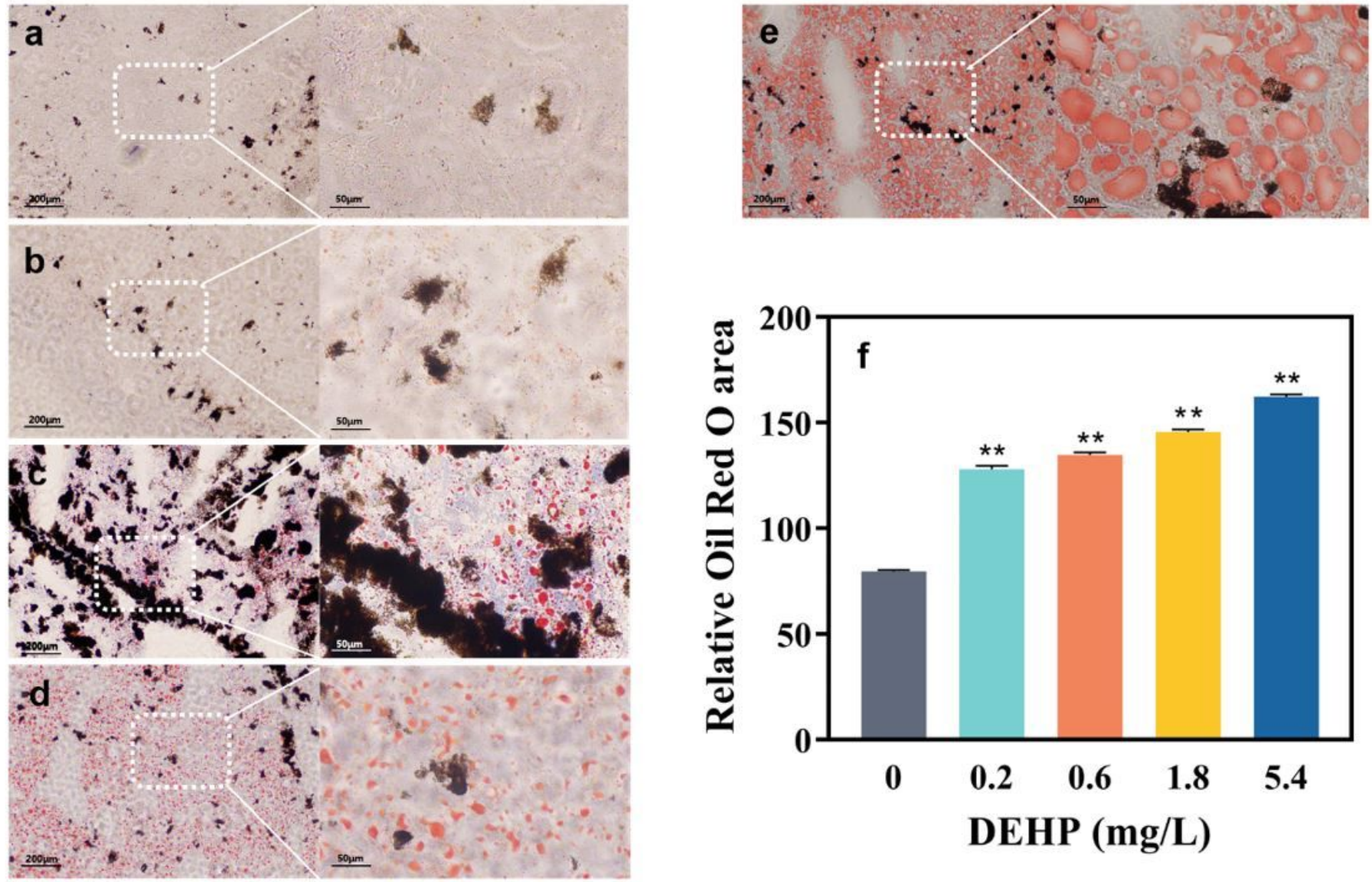

Figure 3

Histopathological images of Oil Red $O$ staining in the livers of male X. tropicalis under under 100x and 400x magnifications (a-e). (f) Oil Red 0-stained area in the livers. a, b, c, d and e represent livers from 0 , $0.2,0.6,1.8$ and $5.4 \mathrm{mg} / \mathrm{L}$ DEHP-treated groups, respectively; ${ }^{* *} \mathrm{P}<0.01$, there is a significant difference from the control group; $n=5$.) 

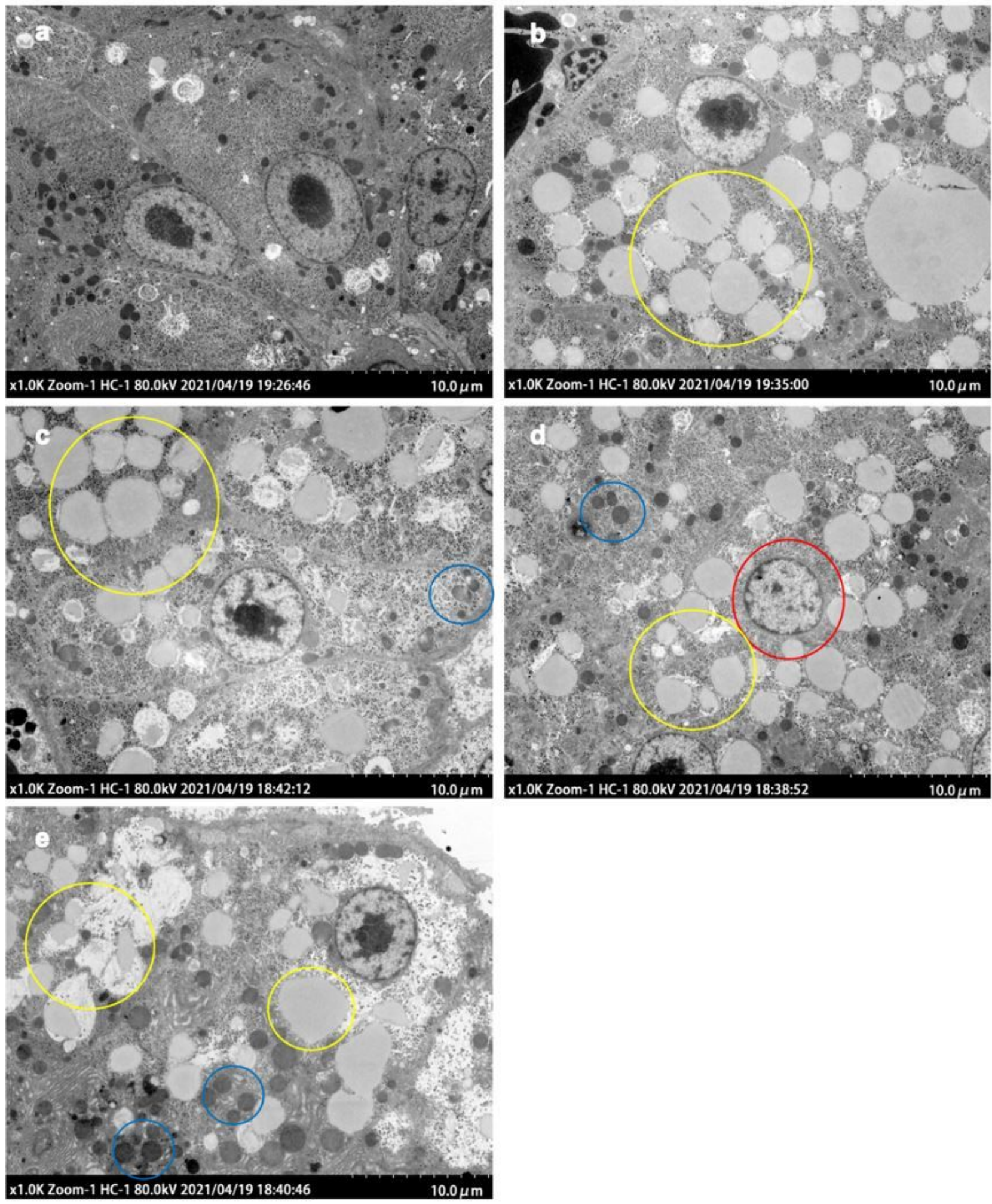

\section{Figure 4}

The ultrastructure of livers of male X. tropicalis post-DEHP exposure. (Yellow circle, blue circle, and red circle indicate lipid accumulation, smaller and swollen mitochondria, and hepatocytes with disordered nucleoli, respectively; $a, b, c, d$ and e represent livers from $0,0.2,0.6,1.8$ and $5.4 \mathrm{mg} / \mathrm{L}$ DEHP-treated groups, respectively; Scale bar: $10.0 \mu \mathrm{m}$.) 

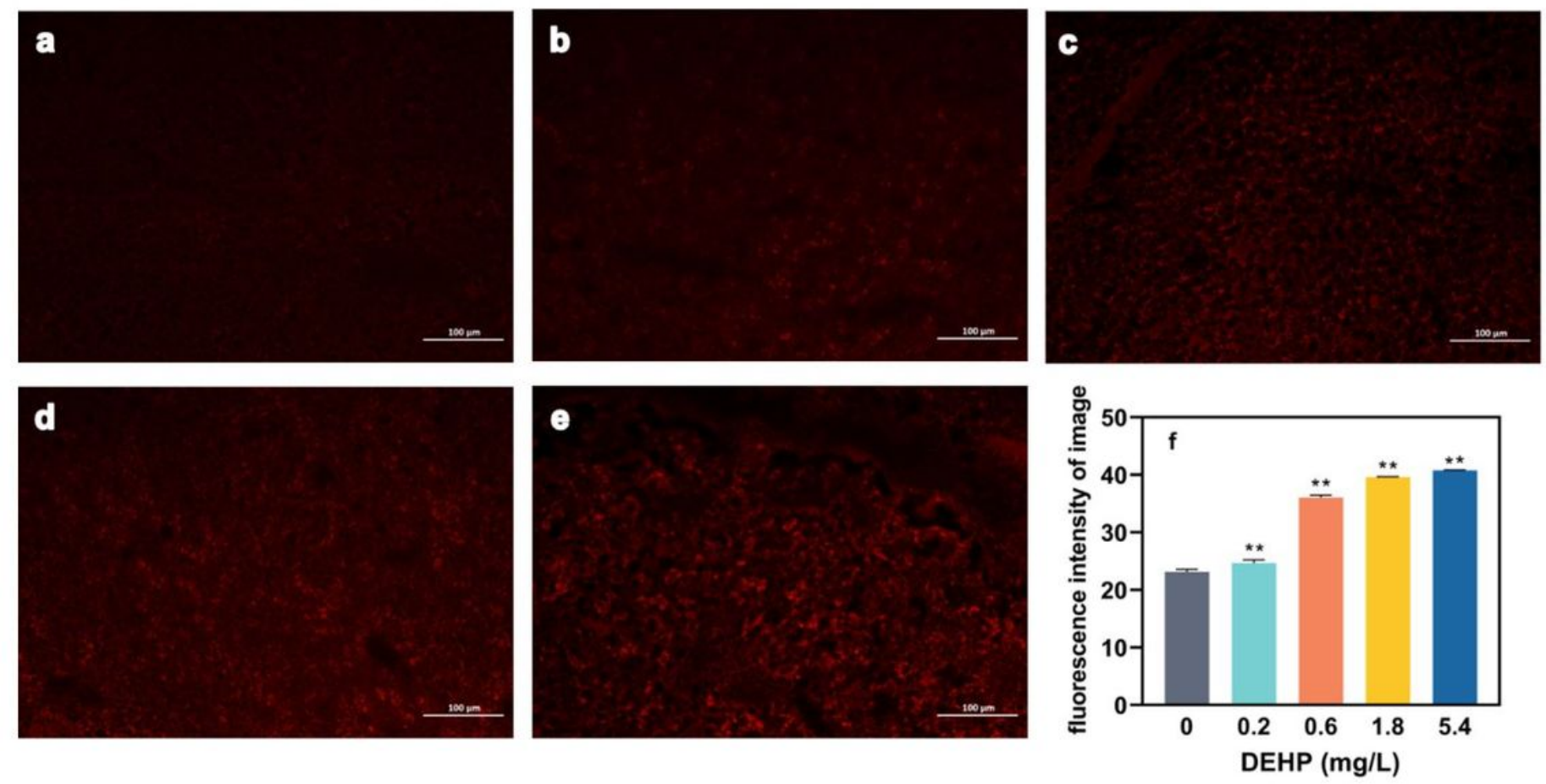

\section{Figure 5}

Reactive oxygen species (ROS) production in the livers of male X. tropicalis post-DEHP exposure. (a-e) Fluorescence images of the livers under $100 \times$ magnification. (f) Fluorescence intensity in the livers of the different DEHP groups. (a, b, c, d and e represent livers from $0,0.2,0.6,1.8$ and $5.4 \mathrm{mg} / \mathrm{L}$ DEHP-treated groups, respectively; ${ }^{\star *} P<0.01$, there is a significant difference from the control group; $n=3$.) 

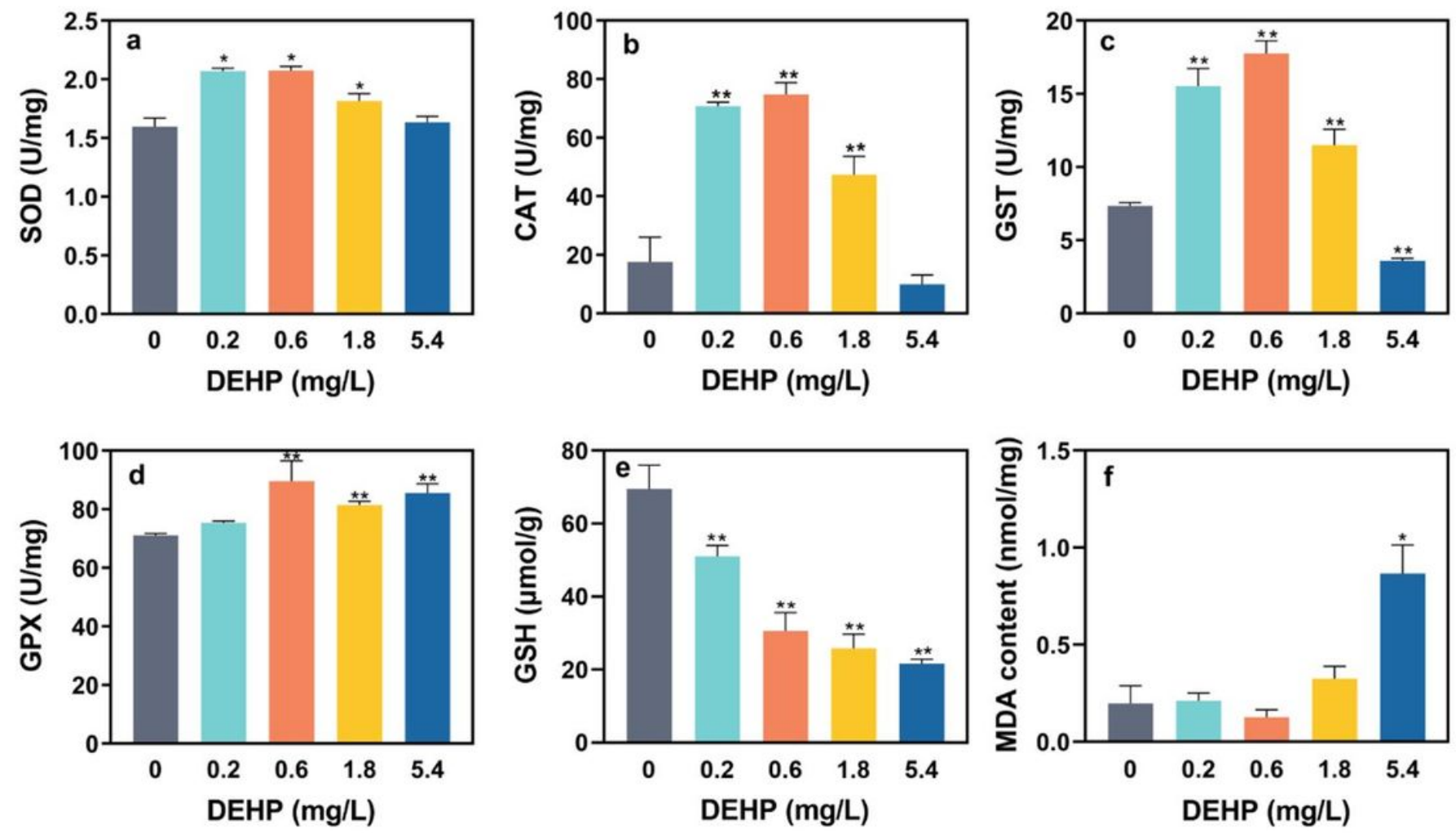

Figure 6

The content of antioxidants and indicator of oxidative damage in the livers of male X. tropicalis postDEHP exposure. (a-d) The activity of antioxidant substances in the livers of male $X$. tropicalis. (f) Contents of malondialdehyde of the livers of male X. tropicalis. ( ${ }^{*} P<0.05,{ }^{*} \mathrm{P}<0.01$, there is a significant difference from the control group.) 

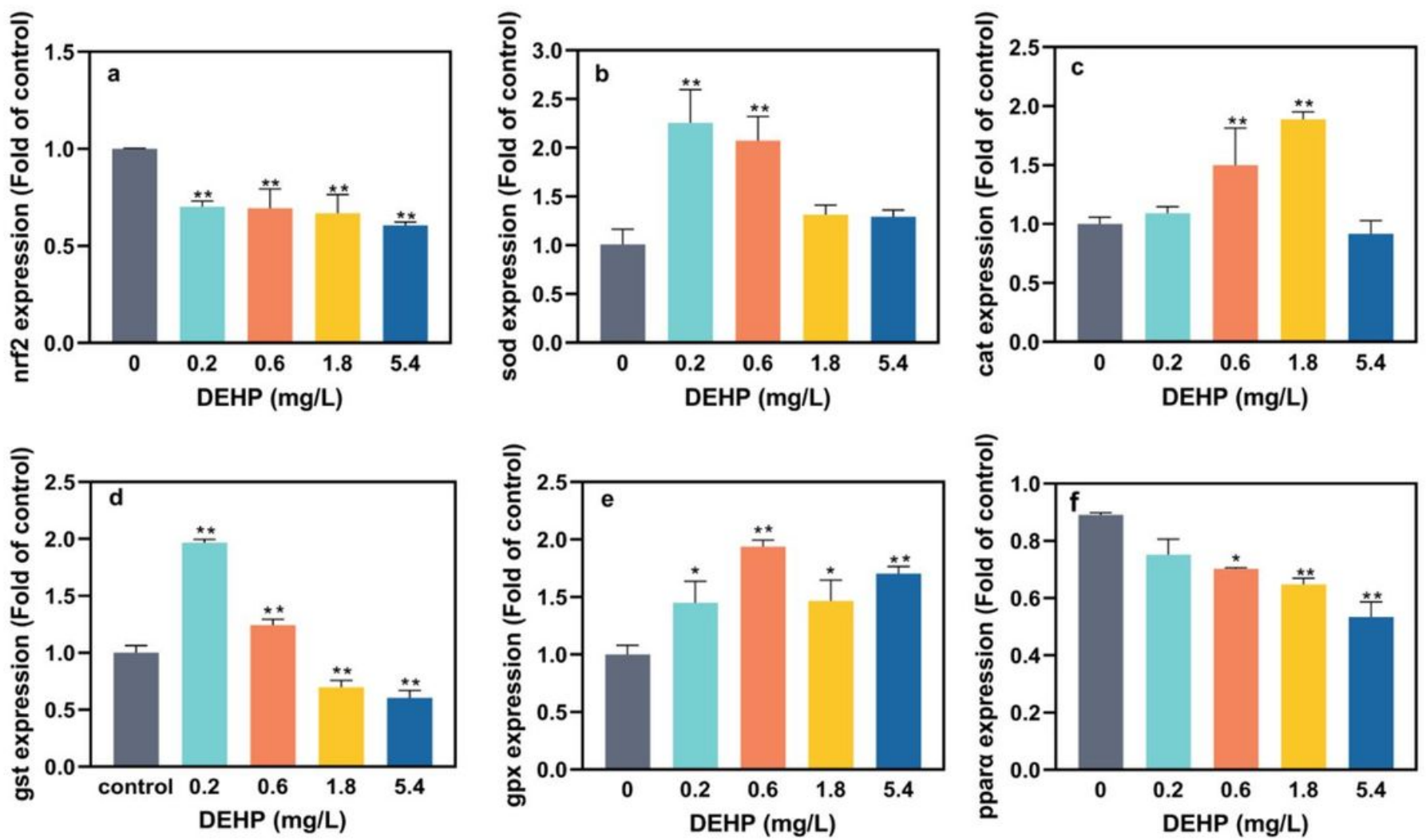

Figure 7

The relative expression of genes in the livers of male X. tropicalis post-DEHP exposure. (a-e) Genes related to oxidative stress. (f) Gene related to lipid metabolism. ( ${ }^{*} P<0.05$. ${ }^{\star *} P<0.01$, there is a significant difference from the control group.)

\section{Supplementary Files}

This is a list of supplementary files associated with this preprint. Click to download.

- ESM.docx 